\title{
OPEN Induction of CTH expression in response to amino acid starvation confers resistance to anti-LAT1 therapy in MDA-MB-231 cells
}

\author{
Takashi Yamaga $^{1}$, Junichi Suehiro ${ }^{1}$, Youichiro Wada ${ }^{2} \&$ Hiroyuki Sakurai ${ }^{1 凶}$
}

L type amino acid transporter 1 (LAT1) is an attractive molecular target for cancer therapy because of its overexpression in many cancer cells. JPH203, a selective LAT1 inhibitor, causes amino acid deprivation and suppresses cancer cell proliferation. However, several cancer cells showed resistance to amino acid deprivation. In this study, we aimed to elucidate the molecular mechanism of different sensitivity between 2 breast cancer cells to anti-LAT1 therapy. MDA-MB-231 cells were more resistant to growth suppression effect of JPH203 than T-47D cells (IC50 was $200 \pm 12.5 \mu \mathrm{M}$ for MDA-MB-231, and $5 \pm 1.1 \mu \mathrm{M}$ for T-47D cells; $\mathrm{p}<0.05$ ). Transcriptome and biochemical analysis were done in these cells in the presence/absence of JPH203. JPH203 induced intracellular amino acid deprivation stress in both cells, but it upregulated cystathionine $\gamma$ lyase (CTH), an enzyme for synthesis of antioxidants, only in MDA-MB-231 cells. Moreover, siRNA-mediated CTH knockdown induced oxidative stress in response to JPH203 leading to decreased cell viability in MDA-MB-231 cells. These results suggest that activation of anti-oxidation pathways in response to amino acid deprivation confers resistance to antiLAT1 therapy.

L-type amino acid transporter (LAT) family are membrane proteins that transport large neutral amino acids across the cell membrane, which consist of four members (LAT1, LAT2, LAT3 and LAT4) ${ }^{1-5}$. Among them, LAT1 which forms a functional heterodimer with $4 \mathrm{~F} 2$ heavy chain $(4 \mathrm{~F} 2 \mathrm{hc})$ has been considered to be a promising target for cancer therapy ${ }^{5,6}$. Its expression levels are high in the fetal tissue and restricted to the barrier such as blood brain barrier or cells with rapid proliferation such as bone marrow in adults ${ }^{7}$. Many tumor cells express LAT1 and its levels of expression are correlated with the aggressiveness of the malignancy ${ }^{8,9}$. In adult non-tumor cells, large neutral amino acids are transported by LAT2 $2^{10,11}$. This tumor selective expression pattern together with novel mode of action, i.e. restricting amino acids delivery specifically for cancer cells, attracted the attention of many investigators. Endou et al. developed JPH203, a specific competitive inhibitor for LAT1, which is now in clinical trial in Japan ${ }^{12}$.

Restricting essential amino acids uptake into the tumor cell suppresses its proliferation via inhibition of mammalian target of rapamycin (mTOR)-p70S6 Kinase (p70S6K) pathway ${ }^{13-15}$. If we assume that the sensitivity of mTOR to essential amino acids are similar across the cells, the potency of JPH203 for a particular cell would be predicted by the expression levels of LAT1. However, the potency of JPH203 on growth suppression was reported to be different among various cancer cell lines that express similar levels of LAT1 ${ }^{16}$.

In addition to suppressing mTOR pathway, genetic inhibition or JPH203 treatment reported to activate amino acid stress response pathway, which consists of general control nonderepressible 2 (GCN2)- eukaryotic Initiation Factor $2 \alpha$ (eIF2 $\alpha$ ) - activating transcription factor 4 (ATF4) $)^{17}$. When cells are depleted of amino acids, GCN2 is activated by phosphorylation and subsequently phosphorylates eIF2 $\alpha$, which leads to inhibition in general protein translation. Phosphorylated eIF2 $\alpha$ promotes ATF4 translation in the face of inhibition of general protein translation ${ }^{18}$. Upregulation of ATF4 may facilitate apoptosis of cancer cells in some circumstances ${ }^{19}$, while it may also promote cancer cell survival and tumorigenesis ${ }^{20}$. One of the downstream molecules regulated by ATF 4

${ }^{1}$ Department of Pharmacology and Toxicology, Kyorin University School of Medicine, 6-20-2, Shinkawa, Mitaka, Tokyo 181-8611, Japan. 'Isotope Science Center, The University of Tokyo, 2-11-16, Yayoi, Bunkyo-ku, Tokyo 113-0032, Japan. ${ }^{\varpi}$ email: hsakurai@ks.kyorin-u.ac.jp 
A

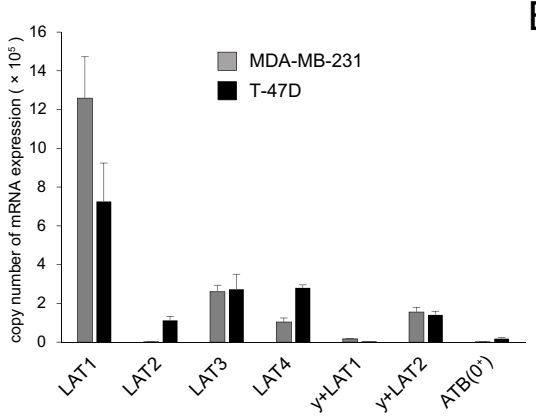

$B$

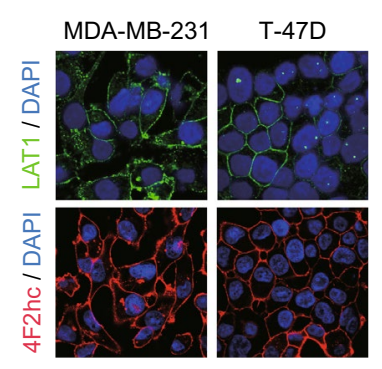

C

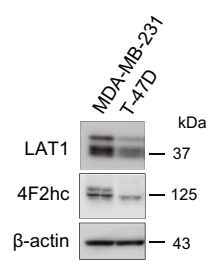

D

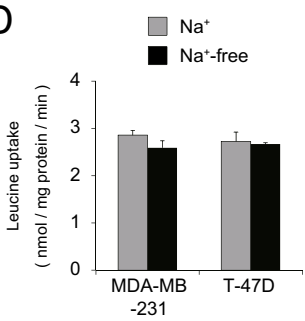

$E$

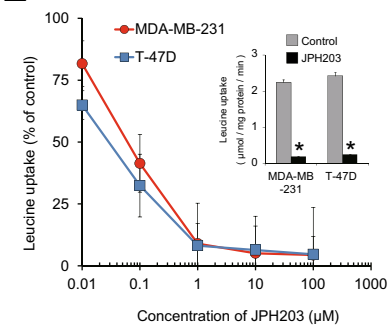

$\mathrm{F}$

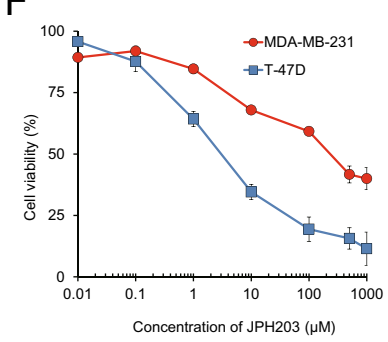

G

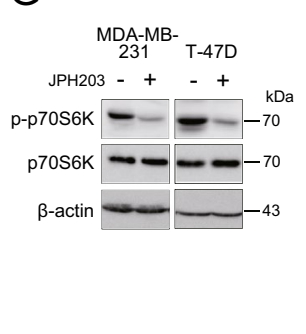

Figure 1. Expression of LAT family and effect of JPH203 in MDA-MB-231 and T-47D cells. (A) Copy number of leucine transporter mRNA in MDA-MB-231 and T-47D cells by qPCR. (B) Immunocytochemistry of LAT1 and 4F2hc in MDA-MB-231 and T-47D cells. Upper columns: LAT1 (green) and DAPI (blue; nuclear staining), lower columns: 4F2hc (red) and DAPI. Scale bars $=20 \mu \mathrm{m}$. (C) Western blot analysis of LAT1 and 4F2hc in MDA-MB-231 and T-47D cells. (D) Radio-labeled leucine uptake was measured in normal $\mathrm{Na}^{+}$-containing or $\mathrm{Na}^{+}$-free buffer. (E) Radio labeled L-leucine uptake was measured under condition of 0.01-100 $\mu \mathrm{M} \mathrm{JPH} 203$. The inset showed leucine uptake at a concentration of $1 \mu \mathrm{M}$ JPH203 in MDA-MB-231 and T-47D cells. ${ }^{*} \mathrm{p}<0.05$. (F) MDA-MB-231 and T-47D cells were incubated for 4 days in the presence of indicated concentration of JPH203, and cell viability was assessed by MTT colorimetric assay. (G) MDA-MB-231 and T-47D cells were incubated for $12 \mathrm{~h}$ in the absence or presence of $100 \mu \mathrm{M}$ (MDA-MB-231) and $5 \mu \mathrm{M}$ (T-47D) of JPH203. The cell lysates were subjected to western blot analysis for phospho-p70S6K, a target molecule downstream of mTOR.

is cystathionine $\gamma$ lyase $(\mathrm{CTH})$, a key enzyme required for synthesis of anti-oxidant molecules such as cysteine and reduced glutathione $(\mathrm{GSH})^{21}$.

We hypothesized that the different degree of anti-proliferative effect of JPH203 among various cancer cells could be explained by the difference in activation of stress responsive pathway downstream of ATF4. For example, if some cells activated pro-apoptotic pathways following ATF4 induction, the proliferation or viability of these cells would be easily suppressed by JPH203. In contrast, if other cells facilitated expression of anti-oxidant molecules downstream of ATF4, these cells would be resistant to the anti-proliferative effect of JPH203.

\section{Results}

JPH203 differentially suppressed the proliferation of MDA-MB-231 and T-47D cells. Two different breast cancer cell lines were used for the experiments; MDA-MB-231 cells derived from triple negative (i.e., no expression of estrogen receptor, progesterone receptor, or HER2) breast cancer, generally classified as more aggressive, treatment resistant cancer, and T-47D cells derived from ductal carcinoma of the breast with estrogen receptor, progesterone receptor, and HER2 expression. We confirmed that LAT1 was the most abundantly expressed leucine transporter both in MDA-MB-231 and T-47D cells by qPCR (Fig. 1A). Its plasma membrane expression was apparent as shown in Fig. 1B. Both in mRNA and protein level, the amount of LAT1 in MDA-MB-231 cells were about 1.5-fold more than that in T-47D cells (Fig. 1A,C).

Both of these cells took up comparable amount of leucine in $\mathrm{Na}^{+}$-free buffer compared with that in $\mathrm{Na}^{+}$ containing buffer (Fig. 1D) and contribution of $\mathrm{Na}^{+}$-dependent leucine uptake was minimal, consistent with low expression of $\mathrm{Na}^{+}$-dependent leucine transporters such as $\mathrm{y}^{+} \mathrm{LAT} 1$ (SLC7A7), $\mathrm{y}^{+} \mathrm{LAT} 2$ (SLC7A6), or ATB $\left(0^{+}\right)$ (SLC6A14) (Fig. 1A). JPH203 has been shown to act as a highly specific competitive inhibitor of LAT1 ${ }^{12}$. IC50 of

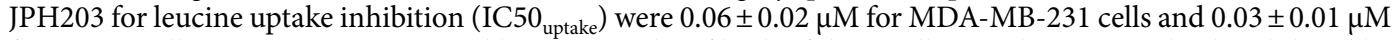
for T-47D cells $(p=0.070$; Fig. $1 \mathrm{E})$ and leucine uptake of both of these cells was almost completely inhibited by $1 \mu \mathrm{M}$ of JPH203 (Fig. 1E, inset). These functional data together with expression data suggest that uptake of large neutral amino acids including leucine into these cells was almost entirely dependent on LAT1.

However, proliferation of T-47D cells was suppressed in the presence of lower concentrations of JPH203 than

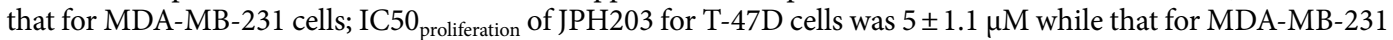
cells was $200 \pm 12.5 \mu \mathrm{M}$ ( $\mathrm{p}<0.05$; Fig. 1F). Hereafter, we describe relative lack of efficacy of JPH203 in suppressing cell proliferation in MDA-MB-231 cells as JPH203 "resistance".

Consistent with previous reports, inhibition of leucine and other branched chain amino acids uptake by JPH203 decreased the activation of mTORC1 pathway and the degree of inhibition was similar between these 
A

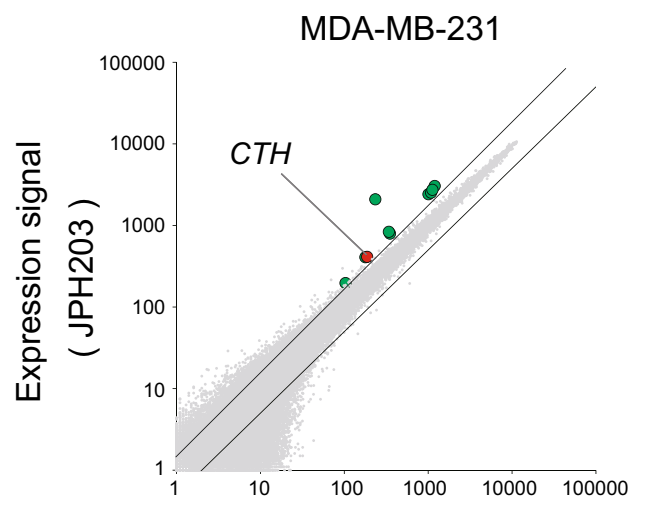

T-47D

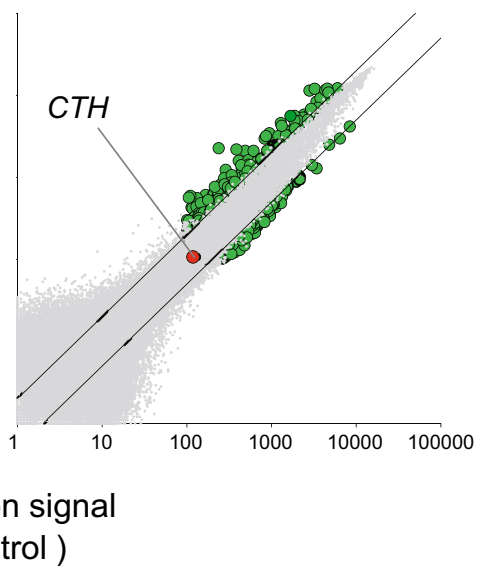

B

Expression signal
$\quad($ Control )

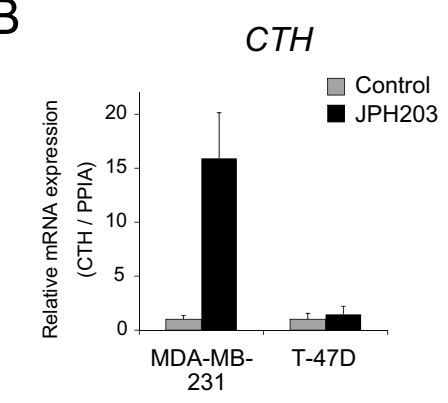

Figure 2. Transcriptome analysis of MDA-MB-231 and T-47D cells in the presence/absence of JPH203. (A) DNA microarray was performed in the presence of $100 \mu \mathrm{M} \mathrm{JPH} 203$ for $24 \mathrm{~h}$ in MDA-MB-231 and T-47D cells. A gene was regarded as differentially expressed if the signal intensity of JPH203 treated condition/signal intensity in control condition was $\leq$ twofold or $\geq$ twofold (green dots, $C T H$ was designated by red dots). (B) $C T H$ mRNA expression in the presence/absence of $100 \mu \mathrm{M}$ JPH203 for $12 \mathrm{~h}$ in MDA-MB-231 and T-47D cells by qPCR.

\begin{tabular}{|c|c|c|c|}
\hline \multirow[b]{2}{*}{ Gene } & \multirow[b]{2}{*}{ Function } & \multicolumn{2}{|c|}{ Ratio : JPH203/control } \\
\hline & & MDA-MB-231 & T-47D \\
\hline ASNS & Asparagine biosynthetic process, cellular response to glucose starvation & 8.57 & 4.29 \\
\hline PSAT1 & L-Serine biosynthetic process & 2.64 & 1.74 \\
\hline CYP1B1 & Metabolism of various endogenous substrates & 2.46 & 1.09 \\
\hline $\mathrm{CTH}$ & Cysteine biosynthetic process, sulfur amino acid catabolic process & 2.46 & 0.66 \\
\hline NNMT & NAD biosynthesis via nicotinamide riboside salvage pathway & 2.38 & 0.50 \\
\hline KIAA1199 & Hyaluronan biosynthetic process & 2.30 & 5.28 \\
\hline
\end{tabular}

Table 1. Differentially expressed genes in MDA-MB-231 cells by JPH203 treatment.

cells (Fig. 1G). In addition, a molecule in the amino acid nutritional stress pathway CHAC1 ${ }^{22}$, which degrades antioxidant GSH, was upregulated in response to JPH203 in both cells (Supplementary Fig. 1), suggesting that some of the reactions to amino acids starvation were commonly observed in both of these cells.

JPH203 treatment induced CTH in MDA-MB-231 cells but not in T-47D cells. Consistent with the relative resistance to JPH203 treatment, the transcriptome of MDA-MB-231 cells was not much affected by JPH203 (Fig. 2A); only 6 genes were differentially expressed in the presence of JPH203 (Table 1). On the other hand, 516 genes were differentially expressed in T-47D cells (Fig. 2A).

Of these 6 genes upregulated by JPH203 treatment in MDA-MB-231 cells, 2 genes, cystathionine $\gamma$ lyase $(C T H)$ and nicotinamide N-methyltransferase (NNMT) were upregulated only in MDA-MB-231 cells (Table 1). Interestingly, both of these enzymes act in an anti-oxidative pathway that generates cysteine from methionine ${ }^{23-25}$. After confirming that $C T H$ mRNA was upregulated in response to JPH203 only in MDA-MB-231 cells by qPCR (Fig. 2B), we decided to focus on $\mathrm{CTH}$, a more downstream enzyme in the process. 


\begin{tabular}{|l|l|l|l|}
\hline & GO term (biological process) & p-value & Gene \\
\hline GO:0031325 & Positive regulation of cellular metabolic process & 0.004 & FASN, ACACA \\
\hline GO:0006520 & Cellular amino acid metabolic process & 0.009 & ATF4, SDSL \\
\hline GO:0000082 & G1/S transition of mitotic cell cycle & 0.019 & MNAT1, CDKN3 \\
\hline GO:0006281 & DNA repair & 0.024 & PARPBP, FANCL \\
\hline GO:0036499 & PERK-mediated unfolded protein response & 0.024 & ATF4, DDIT3 \\
\hline GO:0006974 & Cellular response to DNA damage stimulus & 0.028 & DDIT3, YAP1 \\
\hline GO:2001237 & Negative regulation of extrinsic apoptotic signaling pathway & 0.043 & CTTN, YAP1 \\
\hline GO:0034976 & Response to endoplasmic reticulum stress & 0.068 & ATF4, DDIT3 \\
\hline
\end{tabular}

Table 2. GO enrichment analysis of differentially expressed genes by JPH203 treatment in T-47D cells.

CTH was likely to be induced through GCN2-ATF4 pathway in MDA-MB-231 cells. In order to elucidate the pathway leading to CTH upregulation, differentially expressed genes in T-47D cells in response to JPH203 treatment were analyzed. Amino acid restriction was known to induce cellular stress response known as GCN2-eIF2 $\alpha$-ATF4 pathway and genes related to this pathway were overrepresented among upregulated genes in T-47D cells in response to JPH203 (Table 2) ${ }^{17,26,27}$. Although ATF4 was not differentially expressed in MDAMB-231 cells in microarray experiments, it did show upregulation in response to JPH203 treatment in these cells by qPCR (Fig. 3A). Consistent with the result of transcriptome analysis, ATF4 gene was also upregulated in T-47D cells in response to JPH203 by qPCR (Fig. 3A).

Because activities of GCN2 and eIF2 $\alpha$ were regulated by phosphorylation rather than transcription, their protein level expression and phosphorylation levels were examined. Both in MDA-MB-231 cells and T-47D cells, JPH203 treatment increased phosphorylation of GCN2 and eIF2a without apparent changes in total protein expression levels (Fig. 3B). As expected from qPCR data, ATF4 protein expression was increased in both of these cells by JPH203, but CTH protein expression was increased only in MDA-MB-231 cells in response to JPH203 (Fig. 3B). This increased expression of CTH was abolished by knocking down ATF4 (Fig. 3C), suggesting that ATF4 is at least one of the regulators for CTH expression.

To confirm that CTH is induced by amino acid depletion but not by unknown action of JPH203 per se, both cells were incubated in the medium depleted of LAT1 substrate amino acids, which are essential amino acids and tyrosine. As shown in Fig. 3D, CTH expression was higher at baseline and increased by the treatment much stronger in MDA-MB-231 cells than in T-47D cells. Along the same line, more than $100 \mu \mathrm{M}$ of JPH203 did not increase CTH expression in T-47D cells while those doses of JPH203 clearly upregulate CTH expression in MDAMB-231 cells (Fig. 3E). If there were unknown side effect of JPH203 that stimulates CTH expression, T-47D cells would have increased CTH in response to higher doses of JPH203. Although this is not a direct proof, it is very difficult to argue that the observed upregulation of CTH was due to some unknown side effect (i.e. not mediated by amino acid depletion) of JPH203.

GCN2, ATF4 or CTH knockdown enhances growth inhibitory effect of JPH203 in MDA-MB-231 cells. Previous reports showed that CTH contributed to cancer cell survival against anti-tumor therapy via enhancing antioxidant activities of the cell ${ }^{25}$. To examine whether amino acid starvation stress-mediated CTH induction plays a role in resisting to growth inhibition by JPH203, we performed MTT cell proliferation/viability assay using GCN2, ATF4 or CTH knockdown cells. Two independent siRNA oligos targeted to GCN2, ATF4 and $C T H$ gene (siGCN2 \#1, siGCN2 \#2, siATF4 \#1, siATF4 \#2, siCTH\#1 and siCTH \#2) significantly suppressed protein expression of each gene in both MDA-MB-231 and T-47D cells (Fig. 4A,C,E). siGCN2 \#1 or siGCN2 \#2 oligos significantly decreased cell viability by $17.6 \%$ and by $26.1 \%$ in JPH203-treated MDA-MB-231, respectively (Fig. 4B). Also, siATF4 \#1 or siATF4 \#2 oligos inhibited cell growth by $15.2 \%$ and by $17 \%$ in MDA-MB-231, respectively (Fig. 4D). CTH knockdown (siCTH1 \#1 or siCTH2 \#2) prominently augmented JPH203-mediated growth inhibition by $33.8 \%$ and by $34.5 \%$ in MDA-MB-231, respectively (Figs. 4F). In contrast, GCN2, ATF4 or CTH knockdown did not affect the growth-inhibitory effect of JPH203 in T-47D cells (Fig. 4B,D,F).

JPH203-mediated CTH induction mitigated reactive oxygen species (ROS) release caused by amino acid starvation stress. We next sought to examine whether JPH203-mediated CTH induction attenuated ROS levels derived from amino acid starvation stress. To that end, we employed cell-permeable DCFH-DA, which is a fluorogenic dye to indicate cellular ROS levels, in JPH203-treated cells. ROS production was significantly increased by 2.5 -fold in JPH203-treated T-47D cells, while it was not altered in JPH203-treated MDA-MB-231 cells (Fig. 5A,B). Exogenous $\mathrm{H}_{2} \mathrm{O}_{2}$ led to increased ROS levels by 4.5 -fold and by 4.2 -fold compared with control in both MDA-MB-231 and T-47D cells, respectively.

In CTH knockdown MDA-MB-231 cells, JPH203 treatment increased the amount of ROS by $29 \%$ (siCTH $\# 1$ ) and 63\% (siCTH \#2), respectively (Fig. 5C,D). Thus, CTH upregulation in response to JPH203 treatment is likely to function as enhancing anti-oxidant capacity of MDA-MB-231 cells.

CTH overexpression supported cell survival under JPH203-induced amino acid starvation in T-47D cells. To investigate whether CTH overexpression could attenuate an anti-proliferative effect by JPH203, T-47D cells were transiently transfected with pcDNA3.1-CTH plasmid (Fig. 6A). In its usual culture 
A

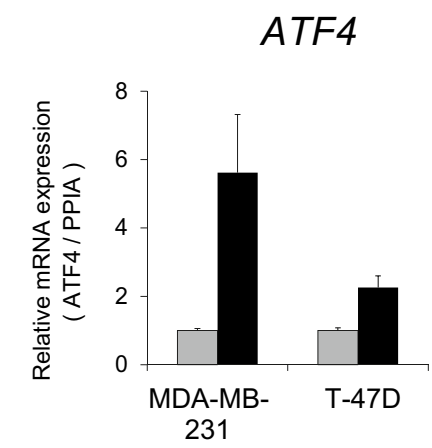

C

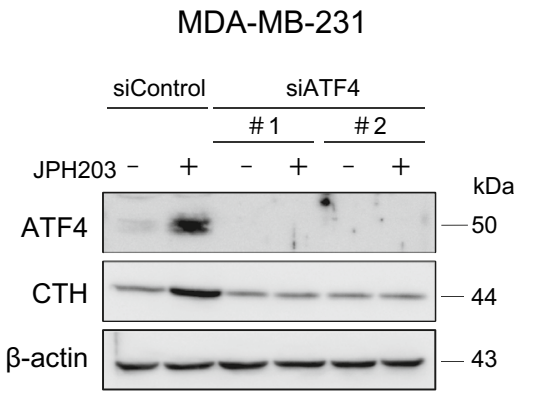

B

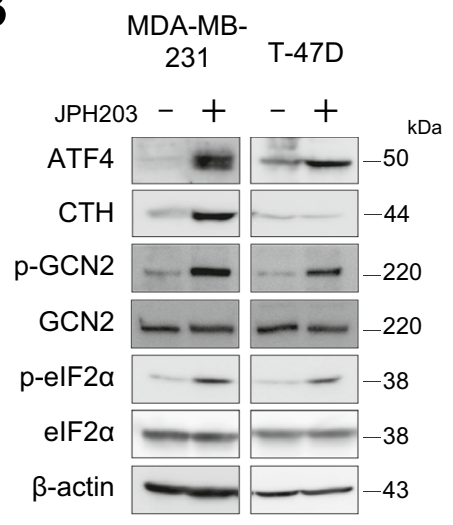

D

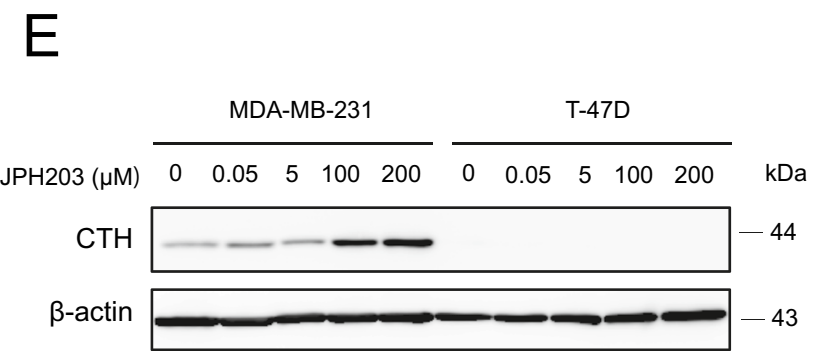

Figure 3. Activation of amino acid starvation stress pathway in cells in response to JPH203 or LAT1 substrate amino acids restriction. (A) ATF4 mRNA expression in the presence/absence of $100 \mu \mathrm{M} \mathrm{JPH} 203$ for $12 \mathrm{~h}$ in MDA-MB-231 and T-47D cells by qPCR. (B) MDA-MB-231 and T-47D cells were incubated for $12 \mathrm{~h}$ in the absence or presence of $100 \mu \mathrm{M}$ (MDA-MB-231) and $5 \mu \mathrm{M}$ (T-47D) of JPH203. The cell lysates were subjected to western blot analysis for ATF4, CTH, phospho-GCN2, phospho-eIF2a. (C) MDA-MB-231 cells were transfected with control (scrambled) or ATF4 siRNA. These transfected cells were incubated in the presence/absence of $100 \mu \mathrm{M}$ of JPH203 for $12 \mathrm{~h}$. The cell lysates were subjected to western blot and probed for CTH and $\beta$-actin (loading control). (D) After MDA-MB-231 and T-47D cells were incubated for $72 \mathrm{~h}$ in amino acid restriction media, the cell lysates were subjected to western blot analysis and probed for CTH and $\beta$-actin (loading control). LAT1 substrate amino acids, which are eight essential amino acids (EAA; L-isoleucine, L-phenylalanine, L-tryptophan, L-valine, L-histidine, L-leucine and L-methionine) and L-tyrosine, were removed from normal RPMI (1.0) to 50\% (0.5), or free (0). (E) MDA-MB-231 and T-47D cells were treated with JPH203 at different concentrations $(0,0.05,5,100$ or $200 \mu \mathrm{M})$ for $48 \mathrm{~h}$. The cell lysates were subjected to western blot analysis for determining $\mathrm{CTH}$ protein levels.

condition in the absence of JPH203 or $\mathrm{H}_{2} \mathrm{O}_{2}$, either mock-transfected or CTH-transfected T-47D cells did not produce much ROS. Increased ROS levels observed in the presence of $\mathrm{JPH} 203$ or $\mathrm{H}_{2} \mathrm{O}_{2}$ were attenuated in 
A

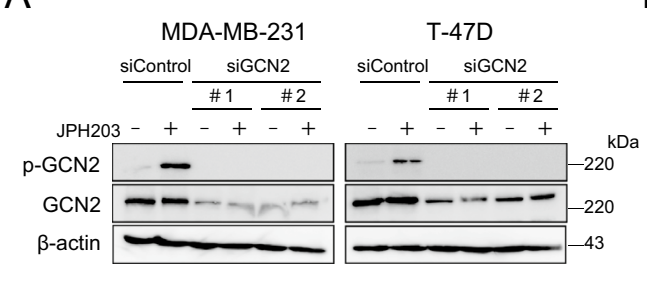

C

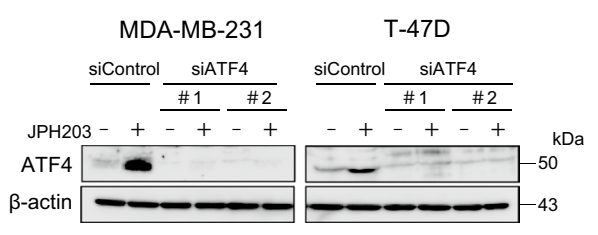

$E$
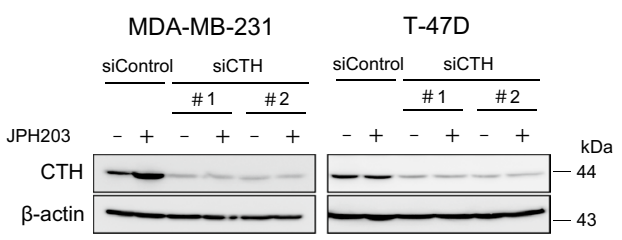

B
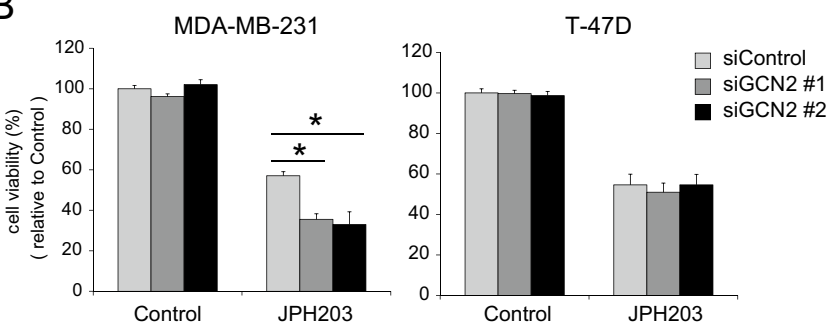

D
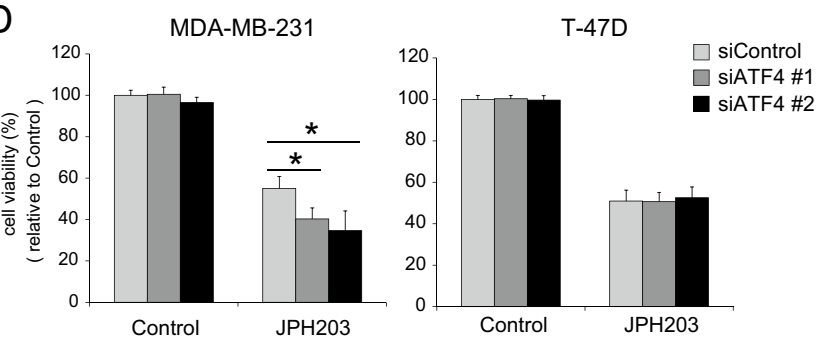

$\mathrm{F}$

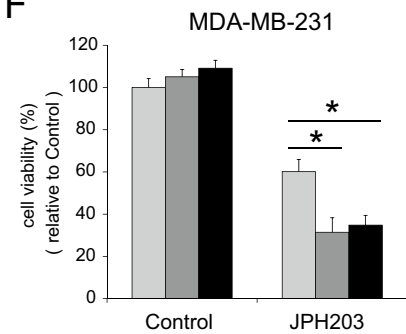

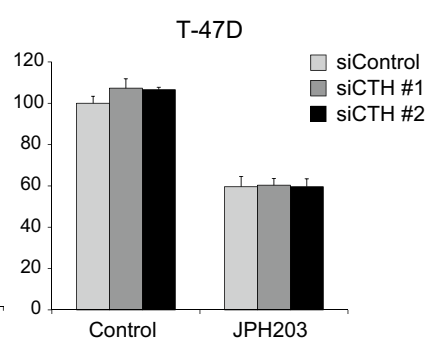

Figure 4. Effect of JPH203 in GCN2, ATF4, or CTH knockdown cells. (A,C,E) MDA-MB-231 and T-47D cells were transfected with control (scrambled) or GCN2 (A), ATF4 (C), CTH (E) siRNA. These transfected cells were incubated in the presence/absence of $100 \mu \mathrm{M}$ (MDA-MB-231) or $5 \mu \mathrm{M}$ (T-47D) of JPH203 for $12 \mathrm{~h}$. The cell lysates were subjected to western blot and probed for each targeted molecule and $\beta$ actin (loading control). $(\mathbf{B}, \mathbf{D}, \mathbf{F})$ These knockdown cells were cultured in the absence or presence of $100 \mu \mathrm{M}$ (MDA-MB-231) or $5 \mu \mathrm{M}$ (T-47D) of JPH203 for $48 \mathrm{~h}$ and cell viability were assessed by MTT assay. ${ }^{*} \mathrm{p}<0.05$.

CTH overexpressed cells by $25 \%$ or by $66 \%$ respectively (Fig. $6 \mathrm{~B}, \mathrm{C}$ ). CTH overexpression significantly increased T-47D cell viability by $13 \%$ in JPH203 and by $8 \%$ in $\mathrm{H}_{2} \mathrm{O}_{2}$, respectively (Fig. $6 \mathrm{D}$ ). Collectively, these findings suggested that increased levels of CTH could reduce ROS levels caused by amino acid deprivation stress and give the cell an ability to survive such a stress.

MDA-MB-231 cells were primed for anti-oxidant production at baseline. Noting that expression levels of CTH was higher in MDA-MB-231 cells than in T-47D cells at baseline (Fig. 3B,D), we looked at microarray data for anti-oxidant related molecules. Not only $\mathrm{CTH}$, but also cystine/glutamic acid transporter $(x C T)$ was expressed more abundantly in MDA-MB-231 cells compared with T-47D cells (Fig. 7). These results suggest that machinery for producing antioxidant GSH and cysteine was more active even at baseline in MDAMB-231 cells.

\section{Discussion}

In this study, we compared 2 breast cancer cell lines, MDA-MB-231 and T-47D cells. Leucine uptake was almost exclusively mediated by LAT1 in both cells and JPH203 inhibited leucine uptake of these cells at IC50 $0_{\text {uptake }}$ of $0.06 \pm 0.02 \mu \mathrm{M}$ for MDA-MB-231 cells and $0.03 \pm 0.01 \mu \mathrm{M}$ for T-47D cells, respectively $(\mathrm{p}=0.07)$. However, MDA-MB-231 cells exhibited "resistance" to anti-proliferative effect of JPH203; IC50 proliferation of $200 \pm 12.5 \mu \mathrm{M}$ for MDA-MB-231 cells and $5 \pm 1.1 \mu \mathrm{M}$ for T-47D cells, respectively $(\mathrm{p}<0.05)$. The discrepancy in IC50

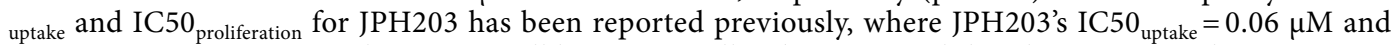
IC $50_{\text {proliferation }}=4.1 \mu \mathrm{M}$ in colon cancer cell line HT29 cells. They reasoned that there exist much more amino acids in the proliferation assay than in the uptake assay ${ }^{12}$. In addition, the time course for leucine uptake was 2 min while the cell proliferation assay took 4 days in our study. Because JPH203 was not an irreversible inhibitor, it is impossible to completely block substrates uptake all through a long incubation period, especially in the media rich in amino acids and in the presence of other leucine transporters such as LAT3 albeit small amount comparing to LAT1. In line with this, Cormerais et al. found that $90 \%$ reduction of LAT1 expression by itself does not lead to growth suppression, suggesting that more than IC90 ${ }_{\text {uptake }}$ of JPH203 (in our case more than $1 \mu \mathrm{M}$ in both cells; Fig. 1E) would require to attain significant growth suppression ${ }^{17}$. The proliferation of T-47D cells 
A

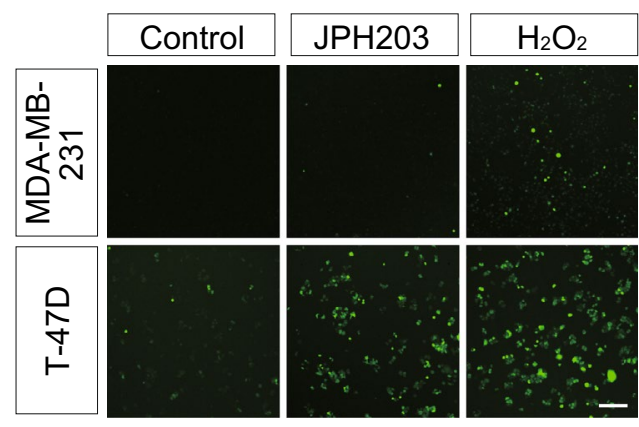

C

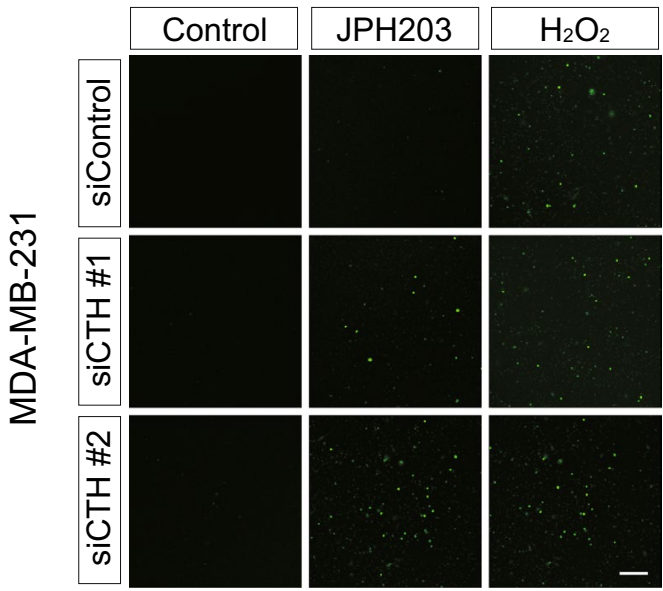

$\mathrm{B}$
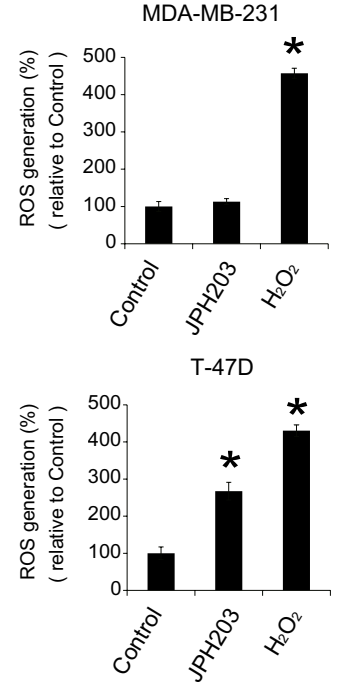

MDA-MB-231

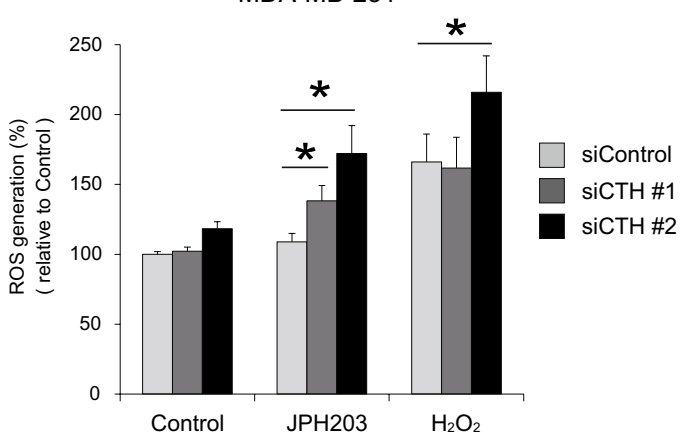

Figure 5. Cellular reactive oxygen spices (ROS) levels in response to JPH203 treatment. (A) Cell-permeable fluorogenic dye, DCFH-DA, was used to observe cellular ROS level after treatment with $100 \mu \mathrm{M} \mathrm{JPH} 203$ for $48 \mathrm{~h}$ in MDA-MB-231 and T-47D cells. Hydrogen peroxide treatment for $20 \mathrm{~min}$ was used as positive control. Scale bar $=100 \mu \mathrm{m}$. (B) Fluorescence intensity of (A) was measured by micro plate-reader. ${ }^{*} \mathrm{p}<0.05$. (C) MDA-MB-231 cells were transfected with control (scrambled) or CTH siRNA followed by incubation in the absence or presence of $100 \mu \mathrm{M} \mathrm{JPH} 203$ for $48 \mathrm{~h}$. Cellular ROS levels were measured with DCFA-DA. Hydrogen peroxide treatment for $20 \mathrm{~min}$ was used as positive control. Scale bar $=100 \mu \mathrm{m}$. (D) Fluorescence intensity of (C) was measured by micro plate-reader. ${ }^{\star} \mathrm{p}<0.05$.

was effectively suppressed by $5 \mu \mathrm{M}$ of JPH203, but that of MDA-MB-231 cells was not (Fig. 1F). Upon obtaining these data, we decided to clarify the reason why the proliferation of MDA-MB-231 cells was not suppressed to the similar degree as T-47D cells in the presence of more than IC50 $0_{\text {uptake }}$ concentrations (i.e. more than $1 \mu \mathrm{M}$ ). The difference in the anti-proliferative effect of JPH203 among cancer cell lines has been reported elsewhere, but no underlying mechanism has been identified to date to the best of our knowledge $\mathrm{e}^{16,28-30}$.

The fact that mTOR-p70S6K pathway was equally suppressed and that a key cellular stress related transcription factor, ATF4, was upregulated in both cells indicates that JPH203 efficiently inhibited essential amino acids uptake into the cells and it induced cellular nutritional stress response to a similar degree between MDA-MB-231 and T-47D cells. Following ATF4 upregulation, these 2 cells upregulated different sets of downstream molecules; anti-oxidant molecules were increased only in MDA-MB-231 cells (Fig. 8). CTH is an enzyme which transforms cystathionine derived from methionine into cysteine and contributes to produce antioxidants such as glutathione and taurine $\mathrm{e}^{31}$. Another gene upregulated in response to JPH203 was NNMT, which catalyzes transmethylation from S-adenosylmethionine to S-adenosylhomocysteine, which can be converted to homocysteine, then to cystathionine, a substrate for $\mathrm{CTH}^{23,32}$. When MDA-MB-231 cells were treated with $100 \mu \mathrm{M}$ of JPH203, their viability was down from $\sim 60 \%$ of vehicle treatment in control siRNA transfected cells to $\sim 30 \%$ in $C T H$ knockdown cells (Fig. 4F), which were almost the same levels of growth suppression observed with $100 \mu \mathrm{M}$ of JPH203 treatment in wild type T-47D cells (Fig. 1F). Thus, it is likely that JPH203 resistance in MDA-MB-231 cells are largely mediated by upregulation of CTH in these cells.

Moreover, at baseline, a molecule that increases intracellular cysteine, cystine/glutamic acid transporter (xCT) was more abundantly expressed in MDA-MB-231 cells than T-47D cells (Fig. 7) ${ }^{33}$. Taken together, both 
A

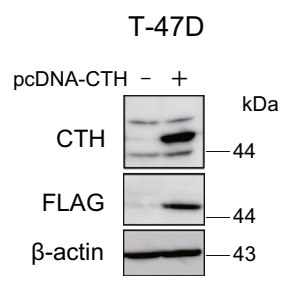

B

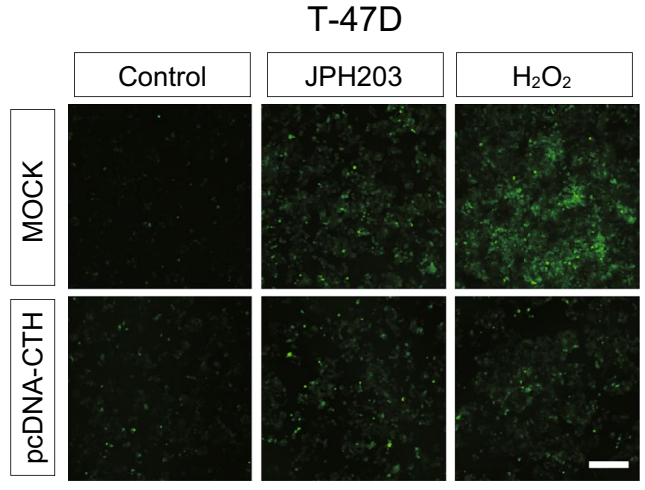

C

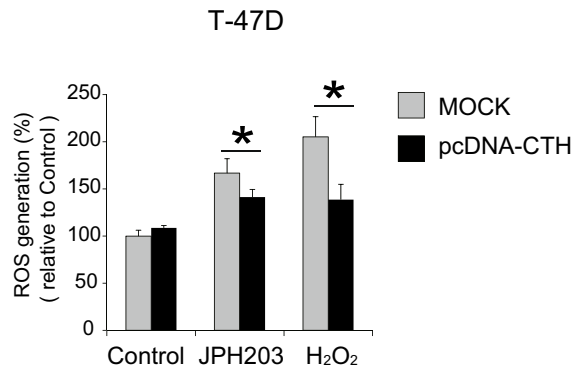

T-47D

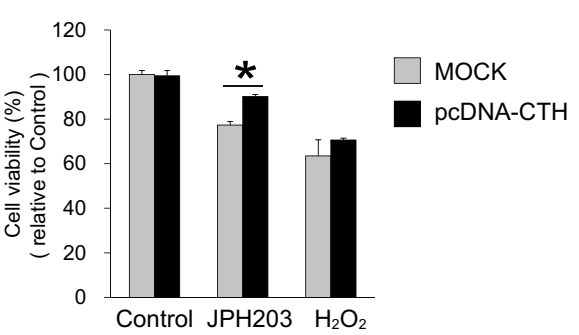

Figure 6. ROS generation and cell viability in response to JPH203 in CTH overexpressed T-47D cells. (A) $1 \mu \mathrm{g}$ of pcDNA3.1-CTH vector or mock vector were transiently transfected into T-47D cells for $24 \mathrm{~h}$. CTH expression and FLAG were confirmed by western blot. (B) After mock or CTH overexpressed T-47D cells were incubated in the absence or presence of $5 \mu \mathrm{M} \mathrm{JPH} 203$ for $48 \mathrm{~h}$, DCFH-DA was applied to observe generation of ROS. Scale bar $=100 \mu \mathrm{m}$. (C) Quantification of intracellular ROS level of (B) by microplate reader. ${ }^{*} \mathrm{p}<0.05$. (D) Cell viability of mock or CTH overexpressed T-47D after incubation in the absence or presence of $5 \mu \mathrm{M} \mathrm{JPH} 203$ for $48 \mathrm{~h}$ was evaluated by MTT assay. ${ }^{*} \mathrm{p}<0.05$.

A

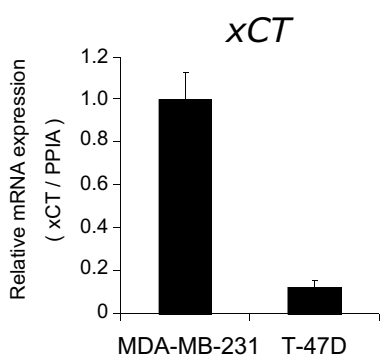

B

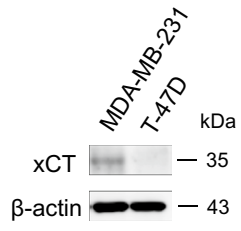

Figure 7. $\mathrm{xCT}$ expression in MDA-MB-231 and T-47D cells. (A) Non-stimulated basal $x$ CT mRNA expression in MDA-MB-231 and T-47D cells by qPCR. (B) Non-stimulated basal xCT protein expression in MDA-MB-231 and T-47D cells by western blot analysis.

at baseline and in response to JPH203, MDA-MB-231 cells appeared to be more prepared to handle ROS load, thereby better survive metabolic stress caused by amino acid depletion than T-47D cells. Given the fact that increased ROS load is the mechanism of inducing cell death in cytotoxic cancer chemotherapy or radiation therapy ${ }^{34}$, it is tempting to speculate that increased anti-oxidative capacity in MDA-MB-231 cells may explain, at least partially, their resistance to classic cancer therapies in addition to JPH203. Whether these findings are generally applicable to triple negative breast cancers is an interesting subject for future research. Regardless, as stated above, upregulation of CTH is likely to be the main mechanism of resistance to JPH203 treatment at least in MDA-MB-231 cells.

To address the question whether increased antioxidant capacity observed in MDA-MB-231 cells in response to JPH203 is due to amino acid depletion or unknown side effect of JPH203, the cells were cultured in the medium depleted of LAT1 substrate amino acids, essential amino acids plus tyrosine (Fig. 3D). This treatment 


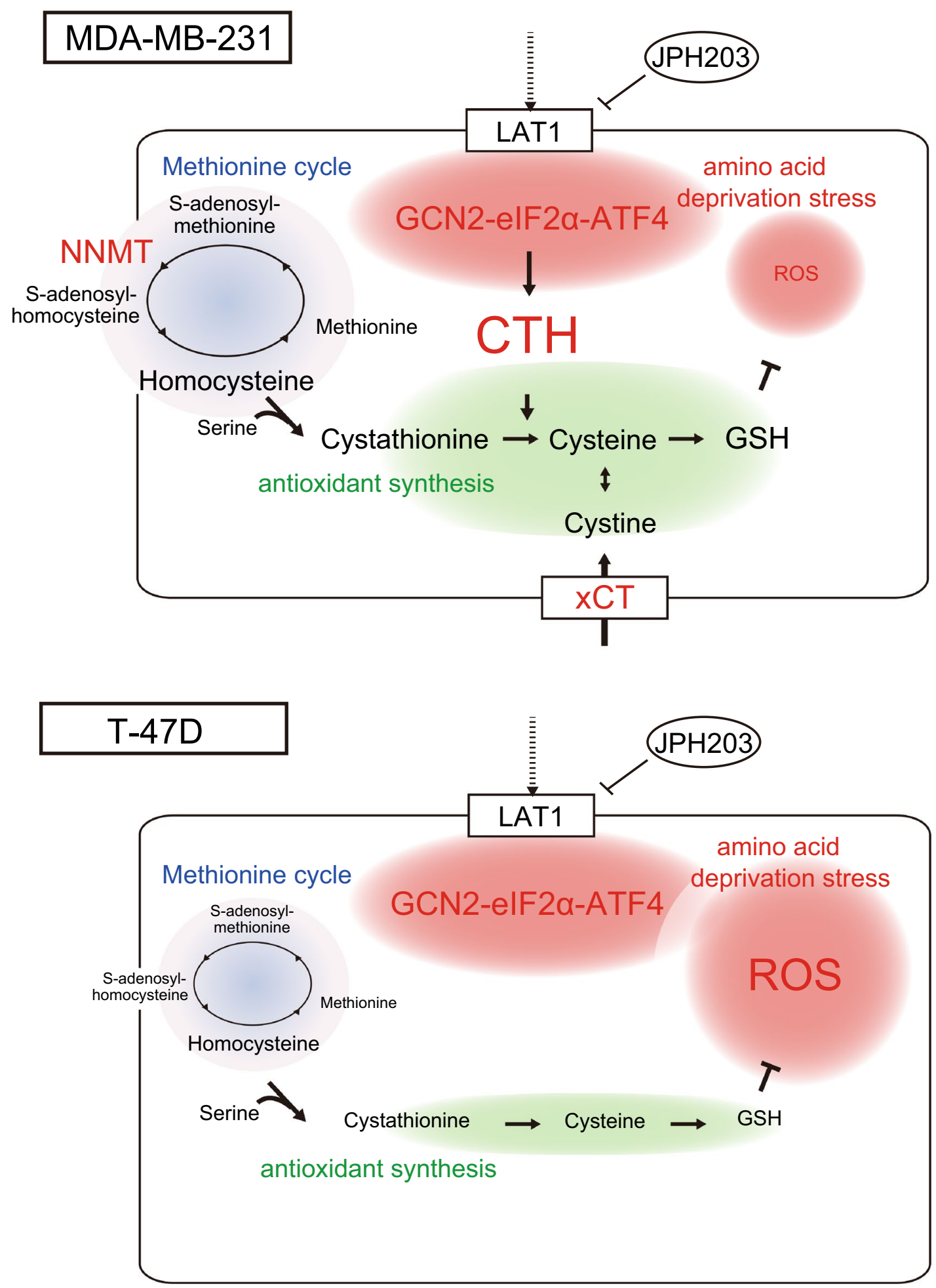

Figure 8. Schematic representation of JPH203-induced amino acid starvation stress pathway in MDA-MB-231 and T-47D cells.

induced upregulation of CTH in MDA-MB-231 cells as seen in JPH203 treatment. Even T-47D cells, which did not increase CTH in the presence of JPH203, slightly increased CTH when substrate amino acids were totally depleted. However, complete depletion of essential amino acids plus tyrosine was impossible with even more than $100 \mu \mathrm{M}$ of JPH203, because JPH203 is a reversible competitive inhibitor in a culture condition rich in substrate amino acids for much longer periods (4 days) than uptake assay ( $2 \mathrm{~min}$ ). In addition, both of these cells expressed small amount of essential amino acid transporters that were not blocked by JPH203 (Fig. 1A). 
Another result showing that treatment with more than $5 \mu \mathrm{M}$ (up to $200 \mu \mathrm{M}$ ) of JPH203 did not increase CTH in T-47D cells (Fig. 3E) speaks against direct (i.e. not mediated by amino acid depletion) upregulation of CTH by JPH203. Taken together, it is likely that increased anti-oxidant capacity in MDA-MB-231 cells in response to JPH203 treatment was due to amino acid depletion, not a side effect of JPH203. In this regard, Cormerais et al. ${ }^{17}$ reported that amino acid stress response of ATF4 upregulation and CGN2 phosphorylation is observed in LAT1 knockout cells. Both T-47D and MDA-MB-231 cells in our study showed the same stress response by JPH203 treatment (Fig. 3B). These results further support our interpretation that JPH203 induced cellular stress response in MDA-MB-231 cells by restricting amino acid uptake through LAT1.

Investigators including us often regard that inhibition of LAT1 causes tumor cell growth suppression through mTORC1 pathway inhibition or simply lack of essential amino acids, but this study implied that cellular antioxidant pathways in response to amino acid deprivation stress may be at least as important for tumor cell viability.

Although ATF4 knockdown abolished CTH upregulation in MDA-MB-231 cells, it is not clear how CTH transcription was differently regulated between these 2 cells downstream of ATF4. Moreover, because we only compared 2 breast cancer cell lines, generalizing our findings to wide variety of cancer cells should be done with caution.

\section{Materials and methods}

Reagent. JPH203((S)-2-amino-3-(4-((5-amino-2-phenylbenzo[d]oxazol-7-yl)methoxy)-3,5-dichlorophenyl)propanoic acid), was kindly provided by J-Pharma Co., Ltd.

Cell culture. MDA-MB-231 and T-47D cells were purchased from American Type culture collection (ATCC, Manassas, VA, USA) and cultured in RPMI1640 medium. (nacalai tesque, Kyoto, Japan) supplemented with $10 \%$ fetal bovine serum (Biowest, VB, FRA), 100 units $/ \mathrm{mL}$ penicillin, and $100 \mathrm{mg} / \mathrm{mL}$ streptomycin at $37^{\circ} \mathrm{C}$ with $5 \%$ $\mathrm{CO}_{2}$.

Immunocytochemistry. Cells were seeded on glass coverslips in 12 -well plate at a density of $1 \times 10^{5}$ cells/ well. After 2-day culture, cells were fixed in cold methanol, permeabilized in buffer $(0.1 \%$ BSA, $0.3 \%$ Triton $\mathrm{X}-100$ in PBS), and blocked with goat serum dilution buffer (10\% goat serum, $1 \%$ Triton X-100, $10 \mathrm{mM}$ glycine in PBS, GSDB). Slides were incubated with LAT1 (1:100, Trans Genic Inc., Fukuoka, Japan) or 4F2hc (1:100, Santa Cruz Biotechnology, Dallas, TX, USA) diluted in GSDB buffer overnight. Cells were incubated with Alexa Fluor 594 conjugated anti-mouse IgG (1:100 Life Technologies, Carlsbad, CA, USA) and DAPI (1:500; Roche, Basel, Switzerland) diluted in GSDB buffer, and then mounted in fluoro-KEEPER Antifade Reagent (nacalai tesque, Kyoto, Japan). Fluoro-images were captured by Fluoview FV500 Laser confocal microscope (Olympus, Tokyo, Japan).

RNA extraction and real-time quantitative PCR analysis. Cells were plated on $60 \mathrm{~mm}$ dishes at a density of $4 \times 10^{5}$ cells/dish and cultured for 2 days. Cells were subsequently treated with $100 \mu \mathrm{M} \mathrm{JPH} 203$ for $12 \mathrm{~h}$ before harvesting total RNA. Total RNA was isolated using Isogen (Nippon Gene, Tokyo, Japan) according to the manufacturer's instruction. The first-strand complementary DNA (cDNA) were synthesized from $1 \mu \mathrm{g}$ of total RNA using MuLV Reverse Transcriptase (Life Technologies, Carlsbad, CA, USA) with oligo dT primer. Real-time PCR was performed with Premix Ex Taq (Takara Bio Inc., Shiga, Japan) or SYBR Select Master Mix (Thermo Fisher Scientific, MA, USA) using 7300 Real-Time PCR system (Thermo Fisher Scientific, MA, USA). Designed primers and probes were shown in Table 3.

Protein extraction and Western blot analysis. Cells were seeded in 6-well plates at a density of $2 \times 10^{5}$ cells/well and cultured for 2 days. Cells were subsequently treated with 0, 0.05, 5, 100 or $200 \mu \mathrm{M} \mathrm{JPH} 203$ for 12 or $48 \mathrm{~h}$ as indicated in each figure legend, and dissolved in Lysis buffer (150 mM NaCl, $0.5 \mathrm{mM}$ EDTA, $\%$ Triton $\mathrm{X}-100$ and $50 \mathrm{mM}$ Tris-HCl, pH 7.4) with cOmplete Mini (Roche, Basel, Switzerland) and PhosSTOP, phosphatase inhibitor (Roche, Basel, Switzerland). $10 \mu \mathrm{g}$ of extracted protein was subjected to SDS-PAGE and transferred to Immobilon-P PVDF membrane (Millipore, KGaA, Darmstadt, Germany). The membrane was blocked with Bullet Blocking One (nacalai tesque, Kyoto, Japan) and incubated with anti-LAT1 (1:1000; Trans Genic Inc., Fukuoka, Japan), anti-4F2hc (1:2000; Santa Cruz Biotechnology, Dallas, TX, USA), anti-phospho-p70S6K (1:1000), anti-p70S6K (1:1000), anti-ATF4 (1:1500), anti-phospho-GCN2 (1:1000), anti-GCN2 (1:1000), antiphospho-EIF2 $\alpha$ (1:1000), anti-EIF2 $\alpha$ (1:1000), anti-CTH (1:1500; all from Cell Signaling Technology, Danvers, TX, USA), anti-xCT (1:1000, Abcam, Cambridge, UK), and anti- $\beta$-actin (1:4000; Sigma-Aldrich, St. Louis, MO, USA) antibodies overnight at $4{ }^{\circ} \mathrm{C}$. After washing, the membrane was incubated with horseradish peroxidase conjugated anti-rabbit IgG or anti-mouse IgG (Jackson Immuno Research Laboratories, West Grove, PA, USA) diluted with Tris buffered saline with Tween 20. Images were obtained using LAS-4000 mini (Fujifilm, Tokyo, Japan). Western blots presented in figures were representative results from three independent experiments.

$\left[{ }^{14} \mathrm{C}\right]$ L-leucine uptake assay. Cells were seeded on 24 -well plates at a density of $1 \times 10^{5}$ cells/well for 2 days before experiment. Cells were subsequently incubated with $\mathrm{Na}^{+}$containing buffer $(125 \mathrm{mM} \mathrm{NaCl}, 4.8 \mathrm{mM} \mathrm{KCl}$, $1.3 \mathrm{mM} \mathrm{CaCl}_{2}, 1.2 \mathrm{mM} \mathrm{MgSO}_{4}, 25 \mathrm{mM}$ HEPES, $1.2 \mathrm{mM} \mathrm{KH}_{2} \mathrm{PO}_{4}$ and $5.6 \mathrm{mM}$ glucose, $\mathrm{pH}$ 7.4) or $\mathrm{Na}^{+}$-free buffer (125 mM choline chloride, $4.8 \mathrm{mM} \mathrm{KCl}, 1.3 \mathrm{mM} \mathrm{CaCl}_{2}, 1.2 \mathrm{mM} \mathrm{MgSO}_{4}, 25 \mathrm{mM} \mathrm{HEPES} 1.2 \mathrm{mM} \mathrm{KH}_{2} \mathrm{PO}_{4}$ and 5.6 mM glucose, $\mathrm{pH} 7.4)$ containing $19 \mu \mathrm{M}$ leucine, $1 \mu \mathrm{M}\left[{ }^{14} \mathrm{C}\right]$ L-leucine $(>8.14 \mathrm{GBq} / \mathrm{mmol}$, Moravek, CA, USA), and $0.01-100 \mu \mathrm{M}$ JPH203 for $2 \mathrm{~min}$ at $37^{\circ} \mathrm{C}$. The cells were solubilized with $0.1 \mathrm{~N} \mathrm{NaOH}$ and cell lysates 


\begin{tabular}{|c|c|c|}
\hline Gene & & Primer pairs and probes \\
\hline \multirow{3}{*}{ LAT1 } & Forward & 5'-GGA AGG GTG ATG TGT CCA ATC T-3' \\
\hline & Reverse & 5'-TTC AAG TAA TTC CAT CCT CCA TAG G-3' \\
\hline & Probe & 5'-FAM-CCC AAC TTC TCA TTT GAA GGC ACC AAA CT-TAMRA-3' \\
\hline \multirow{3}{*}{ LAT2 } & Forward & 5'-AAA TCT GGA GGT GAC TAC TCC TAT GTC-3' \\
\hline & Reverse & 5'-GTA GAT CAC CAG CAC AGC AAT CC-3' \\
\hline & Probe & 5'-FAM-TCT TCG GAG GAC TGG CTG GGT TCC-TAMRA-3' \\
\hline \multirow{3}{*}{ LAT3 } & Forward & 5'-CCC CAA CTC AGG GCA CTG T-3' \\
\hline & Reverse & 5'-GTA GCG TGG TCT GAT GGA TTT G-3' \\
\hline & Probe & 5'-FAM-CTC GGA GAT GCC AGG GAC GGG-TAMRA-3' \\
\hline \multirow{3}{*}{ LAT4 } & Forward & 5'-GCC CCT GGG TAT CGT CAT G-3' \\
\hline & Reverse & 5'-CGT ACG CAA TCA GCA AGC A-3' \\
\hline & Probe & 5'-FAM-CAG CGC CTG CTT CGC GGT TT-TAMRA-3' \\
\hline \multirow{3}{*}{$y+L A T 1$} & Forward & 5'-GCC AAC TAC ATG GTA CAG CCT CTC-3' \\
\hline & Reverse & 5'-TGA AGG TTA AGA GAC AAA TGC AGG CA-3' \\
\hline & Probe & 5'-FAM- CCC TTA TGC TGC CAG CCG CCT GCT-TAMRA-3' \\
\hline \multirow{3}{*}{$y+L A T 2$} & Forward & 5'-TTC AGA TGT CCT TAG CAG TGA TGC-3' \\
\hline & Reverse & 5'-CGA AGA ACA ACC TTG ATG AAG CAA AG-3' \\
\hline & Probe & 5'-FAM- CCC AAA GCA GGA CAG GGC AAC AGC AA-TAMRA-3' \\
\hline \multirow{3}{*}{$A T B\left(0^{+}\right)$} & Forward & 5'-TCA ACA ATT TTA CCT GCA TCA ACG G-3' \\
\hline & Reverse & 5'-GTT GGA GCG CCA CTT TAT TCC AA-3' \\
\hline & Probe & 5'-FAM- AGC CAG GGC AGC TTC CCA GTG AAC AA-TAMRA-3' \\
\hline \multirow{2}{*}{ ATF4 } & Forward & 5'-ACA GCA AGG AGG ATG CCT TC-3' \\
\hline & Reverse & 5'-CAA CGT GGT CAG AAG GTC ATC-3' \\
\hline \multirow{2}{*}{$\mathrm{CTH}$} & Forward & 5'-CAT GAG TTG GTG AAG CGT CAG-3' \\
\hline & Reverse & 5'-AGC TCT CGG CCA GAG TAA ATA-3' \\
\hline \multirow{2}{*}{$x C T$} & Forward & 5'-GCT TTC AAA TGC AGT GGC AGT-3' \\
\hline & Reverse & 5'-AGC AAA CAC ACC ACC GTT CA-3' \\
\hline \multirow{2}{*}{ CHAC1 } & Forward & 5'-CAG GGA GAC ACC TTC CAT CG-3' \\
\hline & Reverse & 5'-GGT ACT TCA GGG CCT TGC TT-3' \\
\hline \multirow{2}{*}{ PPIA } & Forward & 5'-TGG TTC CCA GTT TTT CAT CTG C-3' \\
\hline & Reverse & 5'-CCA TGG CCT CCA CAA TAT TCA-3' \\
\hline
\end{tabular}

Table 3. Primer pairs and probes for real-time PCR.

were added to OptiPhase SuperMix (PerkinElmer, Waltham, MA, USA). The radioactivity was measured by a liquid scintillation counter; LSC-7400 (Hitachi-Aloka Medical, Tokyo, Japan).

Cell proliferation/viability assay. Cells were precultured on 24 -well plates at a density of $5 \times 10^{4}$ cells/well for $24 \mathrm{~h}$ and then treated with $0.01-1000 \mu \mathrm{M}$ JPH203 for 4 days or $48 \mathrm{~h}$. MTT (3-(4,5-dimethylthiazol-2yl)-2, 5 -diphenyltetrazolium bromide) (nacalai tesque, Kyoto, Japan) colorimetric assay was conducted on these cells. The $50 \%$ inhibitory concentration (IC50) of JPH203 was obtained from the dose-response curve.

DNA microarray analysis. Cells were seeded on $60 \mathrm{~mm}$ dishes at a density of $1 \times 10^{5}$ cells and treated with $100 \mu \mathrm{M}$ JPH203 for $24 \mathrm{~h}$. Total RNA was extracted with ISOGEN according to the manufacturer's instruction. DNA microarray analysis was performed using U133 plus 2.0 DNA chip microarray (Affymetrix CA, USA). Data are available at the Gene Expression Omnibus (GEO) under accession: GSE173698.

Amino acid restriction culture. Cells were seeded on 6 -well plates at a density of $1 \times 10^{5}$ cells/well and cultured for $24 \mathrm{~h}$ in RPMI1640 medium supplemented with $10 \%$ fetal bovine serum, 100 units/mL penicillin, and 100 units $/ \mathrm{mL}$ streptomycin. Before amino acid restriction, cells were washed thoroughly with $2 \mathrm{~mL}$ PBS 3 times, and then cultured in RPMI1640-based amino acid restriction culture medium supplemented with small molecule-free dialyzed FBS (Thermo Fisher Scientific, MA, USA), 100 units $/ \mathrm{mL}$ penicillin, $100 \mathrm{mg} / \mathrm{mL}$ streptomycin, and vitamin solution for RPMI1640 (Sigma-Aldrich, St. Louis, MO, USA) for $72 \mathrm{~h}$. Cells were harvested by Lysis buffer with cOmplete Mini and PhosSTOP, phosphatase inhibitor described in "Protein extraction and Western blot analysis" section. The composition of RPMI1640-based amino acid restriction culture media was shown in Supplementary Table S1.

siRNA-mediated knockdown. Cells were seeded on 24 -well plates at a density of $5 \times 10^{4}$ cells/well, and precultured in RPMI1640 medium supplemented with 10\% FBS without antibiotics for 24 h before siRNA 
transfection. Cells were transfected with two independent Silencer select siRNA oligos; siATF4 (\#1=s1702, $\# 2=$ s1703), siGCN2 (\#1=s54067, \#2=s54068), siCTH (\#1=s3710, \#2=s3712 all from Thermo Fisher Scientific, MA, USA), siControl \#1(ON-TARGETplus Non-targeting siRNA \#2; Dharmacon, Chicago, IL, USA) using Lipofectamine RNAi max Reagent (Thermo Fisher Scientific, MA, USA), and incubated for $8 \mathrm{~h}$. These cells were incubated in the presence or absence of JPH203 for $48 \mathrm{~h}$ and their proliferation/viability was assessed by MTT assay. 100 or $5 \mu \mathrm{M}$ of JPH203 was added to MDA-MB-231 or T-47D cells, respectively.

Intracellular ROS detection. Cells were plated on 24 -well plates at a density of $7.5 \times 10^{4}$ cells/well, precultured for $24 \mathrm{~h}$, and treated with $100 \mu \mathrm{M} \mathrm{JPH} 203$ for $48 \mathrm{~h}$. Cells were washed 3 times with PBS, and treated with $10 \mu \mathrm{M}$ 2, 7-Dichlorodihydrofluorescein-diacetate (DCFH-DA) (Sigma-Aldrich, St. Louis, MO, USA) for $30 \mathrm{~min}$. Fluorescence intensity was measured using microplate-reader, and photographed by fluorescence microscope. For a positive control of ROS generation, cells were treated with $500 \mu \mathrm{M} \mathrm{H}_{2} \mathrm{O}_{2}$ for 20 min after DCFH-DA loading.

pcDNA3.1-CTH plasmid construction. The PCR products of CTH fused with $3 \times$ FLAG tags were cloned into the pcDNA3.1(-) vector and transformed into E. coli JM109. Sequences of primer sets were shown as follows: $C T H$ forward; 5'-CCG GAA TTC ATG CAG GAA AAA GAC GCC TC-3', CTH reverse; 5'-GCC GGT ACC CTA GCT GTG ACT TCC ACT TG-3'. T-47D cells were seeded on 24 well plates at a density of $7.5 \times 10^{4}$ cells/well for $24 \mathrm{~h}$, and transfected with $1 \mu \mathrm{g}$ of cDNA3.1-CTH or pcDNA3.1 (MOCK) for $24 \mathrm{~h}$ using Lipofectamine 3000 (Thermo Fisher Scientific, MA, USA) according to the manufacturer's instruction.

Statistical analysis. Experiments were repeated 3 times and the data are expressed as mean \pm standard error. Statistical analysis was performed using Student's t -test (unpaired, two-tailed) and p-value of 0.05 was chosen as the threshold for statistical significance.

Original blot data. As per the policy of the journal, original blot images of composite figures were presented in Supplementary Fig. 2.

Received: 5 May 2021; Accepted: 5 January 2022

Published online: 19 January 2022

\section{References}

1. Mastroberardino, L. et al. Amino-acid transport by heterodimers of 4F2hc/CD98 and members of a permease family. Nature 395, 288-291. https://doi.org/10.1038/26246 (1998).

2. Babu, E. et al. Identification of a novel system L amino acid transporter structurally distinct from heterodimeric amino acid transporters. J. Biol. Chem. 278, 43838-43845. https://doi.org/10.1074/jbc.M305221200 (2003).

3. Pineda, M. et al. Identification of a membrane protein, LAT-2, that Co-expresses with 4F2 heavy chain, an L-type amino acid transport activity with broad specificity for small and large zwitterionic amino acids. J. Biol. Chem. 274, 19738-19744. https://doi. org/10.1074/jbc.274.28.19738 (1999).

4. Bodoy, S. et al. Identification of LAT4, a novel amino acid transporter with system L activity. J. Biol. Chem. 280, 12002-12011. https://doi.org/10.1074/jbc.M408638200 (2005).

5. Kanai, Y. et al. Expression cloning and characterization of a transporter for large neutral amino acids activated by the heavy chain of 4F2 antigen (CD98). J. Biol. Chem. 273, 23629-23632. https://doi.org/10.1074/jbc.273.37.23629 (1998).

6. Kaira, K. et al. Prognostic significance of L-type amino acid transporter 1 (LAT1) and 4F2 heavy chain (CD98) expression in early stage squamous cell carcinoma of the lung. Cancer Sci. 100, 248-254. https://doi.org/10.1111/j.1349-7006.2008.01029.x (2009).

7. Yanagida, O. et al. Human L-type amino acid transporter 1 (LAT1): Characterization of function and expression in tumor cell lines. Biochim. Biophys. Acta 1514, 291-302. https://doi.org/10.1016/s0005-2736(01)00384-4 (2001).

8. Sakata, T. et al. L-type amino-acid transporter 1 as a novel biomarker for high-grade malignancy in prostate cancer. Pathol. Int. 59, 7-18. https://doi.org/10.1111/j.1440-1827.2008.02319.x (2009).

9. Ichinoe, M. et al. High expression of L-type amino-acid transporter 1 (LAT1) in gastric carcinomas: Comparison with noncancerous lesions. Pathol. Int. 61, 281-289. https://doi.org/10.1111/j.1440-1827.2011.02650.x (2011).

10. Segawa, H. et al. Identification and functional characterization of a $\mathrm{Na}$--independent neutral amino acid transporter with broad substrate selectivity. J. Biol. Chem. 274, 19745-19751. https://doi.org/10.1074/jbc.274.28.19745 (1999).

11. Kim, D. K. et al. Characterization of the system L amino acid transporter in T24 human bladder carcinoma cells. Biochim. Biophys. Acta 1565, 112-121. https://doi.org/10.1016/s0005-2736(02)00516-3 (2002).

12. Oda, K. et al. L-type amino acid transporter 1 inhibitors inhibit tumor cell growth. Cancer Sci. 101, 173-179. https://doi.org/10. 1111/j.1349-7006.2009.01386.x (2010).

13. Kim, D. H. et al. mTOR interacts with raptor to form a nutrient-sensitive complex that signals to the cell growth machinery. Cell 110, 163-175. https://doi.org/10.1016/s0092-8674(02)00808-5 (2002).

14. Pavlova, N. N. et al. As extracellular glutamine levels decline, asparagine becomes an essential amino acid. Cell Metab. 27, 428-438. e425. https://doi.org/10.1016/j.cmet.2017.12.006 (2018).

15. Zhang, N. et al. Increased amino acid uptake supports autophagy-deficient cell survival upon glutamine deprivation. Cell Rep. 23, 3006-3020. https://doi.org/10.1016/j.celrep.2018.05.006 (2018).

16. Muto, Y. et al. Different response profiles of gastrointestinal cancer cells to an L-type amino acid transporter inhibitor, JPH203. Anticancer Res. 39, 159-165. https://doi.org/10.21873/anticanres.13092 (2019).

17. Cormerais, Y. et al. Genetic disruption of the multifunctional CD98/LAT1 complex demonstrates the key role of essential amino acid transport in the control of mTORC1 and tumor growth. Cancer Res. 76, 4481-4492. https://doi.org/10.1158/0008-5472.Can15-3376 (2016).

18. Kilberg, M. S., Shan, J. \& Su, N. ATF4-dependent transcription mediates signaling of amino acid limitation. Trends Endocrinol. Metab. 20, 436-443. https://doi.org/10.1016/j.tem.2009.05.008 (2009). 
19. Qing, G. et al. ATF4 regulates MYC-mediated neuroblastoma cell death upon glutamine deprivation. Cancer Cell 22, 631-644. https://doi.org/10.1016/j.ccr.2012.09.021 (2012).

20. Ye, J. \& Koumenis, C. ATF4, an ER stress and hypoxia-inducible transcription factor and its potential role in hypoxia tolerance and tumorigenesis. Curr. Mol. Med. 9, 411-416. https://doi.org/10.2174/156652409788167096 (2009).

21. Dickhout, J. G. et al. Integrated stress response modulates cellular redox state via induction of cystathionine $\gamma$-lyase: Cross-talk between integrated stress response and thiol metabolism. J. Biol. Chem. 287, 7603-7614. https://doi.org/10.1074/jbc.M111.304576 (2012).

22. Chen, M. S. et al. CHAC1 degradation of glutathione enhances cystine-starvation-induced necroptosis and ferroptosis in human triple negative breast cancer cells via the GCN2-eIF2a-ATF4 pathway. Oncotarget 8, 114588-114602. https://doi.org/10.18632/ oncotarget.23055 (2017).

23. Aksoy, S., Szumlanski, C. L. \& Weinshilboum, R. M. Human liver nicotinamide $N$-methyltransferase. cDNA cloning, expression, and biochemical characterization. J. Biol. Chem. 269, 14835-14840 (1994).

24. Valko, M., Rhodes, C. J., Moncol, J., Izakovic, M. \& Mazur, M. Free radicals, metals and antioxidants in oxidative stress-induced cancer. Chem. Biol. Interact. 160, 1-40. https://doi.org/10.1016/j.cbi.2005.12.009 (2006).

25. Leikam, C. et al. Cystathionase mediates senescence evasion in melanocytes and melanoma cells. Oncogene 33, 771-782. https:// doi.org/10.1038/onc.2012.641 (2014).

26. Dever, T. E. et al. Phosphorylation of initiation factor 2 alpha by protein kinase GCN2 mediates gene-specific translational control of GCN4 in yeast. Cell 68, 585-596. https://doi.org/10.1016/0092-8674(92)90193-g (1992).

27. Wek, R. C., Jackson, B. M. \& Hinnebusch, A. G. Juxtaposition of domains homologous to protein kinases and histidyl-tRNA synthetases in GCN2 protein suggests a mechanism for coupling GCN4 expression to amino acid availability. Proc. Natl. Acad. Sci. U. S. A. 86, 4579-4583. https://doi.org/10.1073/pnas.86.12.4579 (1989).

28. Ueno, S. et al. Metformin enhances anti-tumor effect of L-type amino acid transporter 1 (LAT1) inhibitor. J. Pharmacol. Sci. 131, 110-117. https://doi.org/10.1016/j.jphs.2016.04.021 (2016).

29. Otsuki, H. et al. Prostate cancer cells in different androgen receptor status employ different leucine transporters. Prostate 77, 222-233. https://doi.org/10.1002/pros.23263 (2017).

30. Yothaisong, S. et al. Inhibition of l-type amino acid transporter 1 activity as a new therapeutic target for cholangiocarcinoma treatment. Tumour Biol. 39, 1010428317694545. https://doi.org/10.1177/1010428317694545 (2017).

31. Ryu, C. S. et al. Elevation of cysteine consumption in tamoxifen-resistant MCF-7 cells. Biochem. Pharmacol. 85, 197-206. https:// doi.org/10.1016/j.bcp.2012.10.021 (2013).

32. Cantoni, G. L. Methylation of nicotinamide with soluble enzyme system from rat liver. J. Biol. Chem. 189, 203-216 (1951).

33. Sato, H., Tamba, M., Ishii, T. \& Bannai, S. Cloning and expression of a plasma membrane cystine/glutamate exchange transporter composed of two distinct proteins. J. Biol. Chem. 274, 11455-11458. https://doi.org/10.1074/jbc.274.17.11455 (1999).

34. Wang, J. \& Yi, J. Cancer cell killing via ROS: To increase or decrease, that is the question. Cancer Biol. Ther. 7, 1875-1884. https:// doi.org/10.4161/cbt.7.12.7067 (2008).

\section{Acknowledgements}

We thank J-pharma Co., Ltd. (Yokohama, Kanagawa, Japan) for providing JPH203, and Ms. Akashi Taguchi of The Research Center for Advanced Science and Technology, The University of Tokyo for microarray analysis. We also thank members of the Department of Pharmacology, Kyorin University School of Medicine for helpful discussion and technical assistance.

\section{Author contributions}

T.Y. and H.S. conceived the research questions and wrote the manuscript text. T.Y. and J.S. performed most of the experiments and prepared all figures. Y.W. performed and analyzed microarray experiments. All authors reviewed the manuscript.

\section{Competing interests}

The authors declare no competing interests.

\section{Additional information}

Supplementary Information The online version contains supplementary material available at https://doi.org/ 10.1038/s41598-022-04987-5.

Correspondence and requests for materials should be addressed to H.S.

Reprints and permissions information is available at www.nature.com/reprints.

Publisher's note Springer Nature remains neutral with regard to jurisdictional claims in published maps and institutional affiliations.

(1) Open Access This article is licensed under a Creative Commons Attribution 4.0 International cc) License, which permits use, sharing, adaptation, distribution and reproduction in any medium or format, as long as you give appropriate credit to the original author(s) and the source, provide a link to the Creative Commons licence, and indicate if changes were made. The images or other third party material in this article are included in the article's Creative Commons licence, unless indicated otherwise in a credit line to the material. If material is not included in the article's Creative Commons licence and your intended use is not permitted by statutory regulation or exceeds the permitted use, you will need to obtain permission directly from the copyright holder. To view a copy of this licence, visit http://creativecommons.org/licenses/by/4.0/.

(C) The Author(s) 2022 